\title{
PERANCANGAN SISTEM INFORMASI PEMESANAN MAKANAN PADA BERKAH CATERING PADANG PANJANG MENGGUNAKAN MICROSOFT VISUAL BASSIC 6.0
}

\author{
Yulia Jihan SY ${ }^{1}$, Ramanda Putra ${ }^{2}$ \\ ${ }^{1,2}$ Program Studi Manajemen Informatika \\ Akademi Manajemen Informatika \& Komputer (AMIK) "Boekittinggi" \\ Email:syahila02012015@gmail.com
}

\begin{abstract}
ABSTRAK
Penelitian Perancangan Sistem Informasi Pemesanan Makanan Pada Berkah Catering Padang Panjang dengan Bahasa Pemograman Visual Basic 6.0 dan Mysql, dilakukan mulai tanggal 20 April s/d 20 Mei 2014. Penelitian bertujuan untuk menyediakan suatu program Informasi yang dapat mempercepat proses kerja pada Berkah Catering Padang Panjang. Untuk merealisasikan program ini di gunakan Bahasa Pemograman Visual Basic 6.0. Dari penelitian ini dapat disimpulkan bahwa dengan adanya program aplikasi ini akan sangat membantu dalam sistem informasi Berkah Catering Padang Panjang yang lebih baik untuk masa yang akan datang.
\end{abstract}

Kata Kunci : Berkah Catering Padang Panjang, Visual Basic, Sistem Informasi.

\section{PENDAHULUAN}

Dengan adanya sistem yang berbasis komputer, pelanggan pada sebuah catering akan sangat dipermudah dalam melakukan transaksi pada catering tersebut, salah satunya yaitu dalam hal pemesanan. Dengan adanya transaksi yang berbasis teknologi informasi ini, sangat memungkinkan aplikasi ini akan menarik pelanggan-pelanggan atau konsumen lain dikarnakan transaksi pada catering ini sangat membantu konsumen dalam melakukan pemesanan atau transaksi lain.

Sebagai contoh dalam pemesanan makanan, melakukan transaksi pembayaran, pembuatan nota dan laporan pendapatan.berkah catering sebagai usaha pemesanan makanan belum memperhatikan sistem internalnya, seperti proses pemesanan makanan, proses pembuatan laporan, dan proses yang lain. Semua proses tersebut masih berjalan manual. Hal ini menyebabkan kinerja pada berkah catering kurang maksimal dan kurang efektif. Dengan demikian suatu hal yang lazim apabila penulis mencoba merancang suatu sistem informasi pemesanan catering yang selama ini di kerjakan secara manual dan mengubahnya menjadi sistem yang terkomputerisasi di Berkah Catering.

Berdasarkan uraian di atas penulis ingin mencoba membuat judul penelitian "Perancangan Aplikasi Pemesanan Makanan pada Berkah Catering Padang Panjang Menggunakan Microsoft Visual Basic 6.0”.

\section{PERUMUSAN MASALAH}

Berdasarkan latar belakang masalah yang telah dikemukakan di atas, maka dapat dirumuskan masalahnya yaitu :

1. Bagaimana cara kerja sistem agar dapat mengatasi keterbatasan dalam pemesanan makanan?

2. Bagaimana merancang aplikasi sistem informasi pemesanan makanan dengan menggunakan bahasa pemograman Microsoft Visual Basic 6.0?

3. Bagaimana membuat laporan sejelas mungkin serta jangka waktu penyerahan laporan yang singkat kepada pimpinan berkah catering?

\section{LANDASAN TEORI}

\subsection{Konsep Dasar Sistem Dan Informasi}

Sistem berasal dari bahasa Yunani yaitu systema yang berarti kesatuan atau sekumpulan. Berikut ini definisi sistem dari dua pendekatan:

1. Yang mengarah pada prosedurnya Suatu sistem adalah suatu jaringan kerja dan prosedur-prosedur yang saling berhubungan, berkumpul bersama-sama untuk melakukan suatu kegiatan atau usaha untuk menyelsaikan suatu sasaran tertentu (Jogiyanto HM, 2001:1).

2. Yang mengarah pada komponen dan elemennya

Sistem adalah kumpulan dari elemen-elemen yang berinteraksi untuk mencapai suatu tujuan tertentu (Jogiyanto HM, 2001 :2) 
Bagian terkecil dari sistem disebut sub sistem dan bagian terbesar dari sistem disebut supra sistem. Menurut (Yogianto,1997) suatu sistem mempunyai karakteristik atau sifat-sifat tertentu yaitu :

1. Komponen (Components)

2. Batas Sistem (Boundary)

3. Lingkungan Luar Sistem (Environments)

4. Penghubung (Interface)

5. Masukan (Input)

6. Keluaran (Output)

7. Pengolah (Process)

8. Sasaran (Objectives) / Tujuan (Goal)

\subsection{Pengertian Sistem Informasi}

A.Leitch dan K. Roscoe Davis sebagai berikut :Sistem informasi adalah suatu sistem di dalam suatu organisasi yang mempertemukan kebutuhan pengolahan transaksi harian, mendukung operasi, bersifat manajerial dan kegiatan strategi dari suatu organisasi dan menyediakan pihak luar tertentu dengan laporan-laporan yang diperlukan (Jogiyanto HM, 2001: 11 ).

\subsection{Siklus Hidup Pengembangan Sistem (SDLC)}

SDLC adalah langkah-langkah (pedoman) yang harus diikuti untuk mengembangkan, merancang sebuah sistem. Siklus hidup pengembangan sistem ini adalah seperti kompas didalam merancang sistem. Adapun langkah-langkah dari siklus hidup pengembangan sistem ada beberapa tahapantahapan sebagai berikut :

1. Tahap Kebijakan dan Perencanaan Sistem (System Planning) yaitu mendefinisikan sumber, batas waktu, informasi-informasi lain seputar proyek.

2. Tahap Analisa Sistem (System Analysis) yaitu melakukan analisa terhadap sistem yang sedang berjalan.

3. Tahap Perancangan Sistem (System Design) secara umum bertujuan mendesain system baru yang dapat menyelesaikan masalahmasalah yang dihadapi perusahaan yang diperoleh dari pemilihan alternative system yang terbaik.

4. Tahap Perancangan Sistem (System Design) secara terinci bertujuan mendesain system baru yang dapat menyelesaikan masalahmasalah yang dihadapi perusahaan yang diperoleh dari pemilihan alternative system yang terbaik.
5. Tahap Seleksi Sistem bertujuan untuk seleksi yaitu memilih perangkat keras dan perangkat lunak pada sistem informasi. Pemilih sistem harus memahami konsep dalam memilih perangkat yang digunakan dalam sistem informasi.

6. Tahap Implementasi (System Implementation) bertujuan mengimplementasikan sistem yang baru dan menjamin bahwa sistem yang baru dapat berjalan secara optimal.

7. Tahap Perawatan (Maintenance) bertujuan untuk memastikan bahwa sistem yang digunakan oleh pihak pengguna benar-benar telah stabil dan terbebas dari error dan bug.

\subsection{Alat Bantu Pengembangan Sistem Aliran Sistem Informasi}

Aliran sistem informasi (ASI) merupakan aliran dari semua dokumen maupun laporan serta tembusannya yang terjadi dalam proses pembuatan laporan.

\section{Data Flow Diagram}

Data flow diagram (DFD) adalah program yang menggunakan notasi-notasi yang menggambarkan arus dari sistem. DFD sering digunakan untuk menggambarkan suatu sistem secara logika tanpa mempertimbangkan lingkungan fisik dimana data tersebut mengalir atau lingkungan fisik dimana data tersebut disimpan.

\section{Context Diagram}

Contex diagram adalah gambaran umum dari sistem organisasi yang menunjukan batasan sistem, entity eksternal yang berintegrasi dengan sistem dan adanya informasi yang mengalir diantara entity dan sistem.

\section{Entity Relationship Diagram (ERD)}

Entity adalah suatu objek atau konsep yang dapat diidentifikasi secara dalam suatu data base, relationship adalah suatu hubungan diantara entiti. Jadi Entity Relationship Diagram (ERD) adalah suatu diagram yang menggambarkan diantara entiti-entiti yang terdapat dalam suatu database. 


\subsection{Visual Basic 6.0}

Visual basic pada dasarnya adalah sebuah bahasa pemrograman komputer. Visual Basic 6.0 bekerja dalam lingkup MS-Windows dan dapat memanfaatkan kemampuan MS-Windows secara optimal. Beberapa kemampuan dan manfaat dari Visual Basic 6.0 atau disingkat dengan VB 6.0 adalah:

1. Untuk membuat program aplikasi berbasis windows.

2. Untuk membuat objek-objek pembantu program seperti misalnya aplikasi internet dan sebagainya.

3. Menguji program (debugging) dan menghasilkan program akhirberakhiran EXE yang bersifat executable, atau dapat langsung dijalankan.

\subsection{Tipe Data dan Operator Visual Basic 6.0 Tipe Data}

Data adalah niali mentah yang tidak memiliki arti jika berdiri sendiri. Masingmasing tipe data mewakili batas nilai tersendiri selengkapnya dapat dilihat pada tabel berikut :

\section{Pengertian Operator}

Operator adalah perintah yang memanipulasi nilai atau variable dan memberikan suatu hasil. Macam-macam operator di dalam Visual Basic 6.0 adalah :
a. Operator Aritmatika
b. Operator Perbandingan
c. Operator Logical

\section{Komponen Visual Basic 6.0}

a. Baris Menu

Menu merupakan kumpulan perintah perintah yang dikelompokkan dalam kriteria operasi yang dihasilkan. Visual Basic 6.0 menyediakan tiga belas menu, keterangan masing-masingnya terdapat pada tabel. 1

b. Toolbar

Toolbar adalah tombol-tombol yang mewakili suatu perintah tertentu dari visual basic. Pada visual basic versi 6.0.

c. Form Window

Form window atau jendela form adalah daerah kerja utama dimana kita akan membuat program-program aplikasi visual basic.

d. Toolbox

Toolbox adalah sebuah kotak piranti yang mengandung semua object atau control yang dibutuhkan untuk membentuk suatu program aplikasi. e. Project Explorer

Jendela project explorer adalah jendela yang mengandung semua file dan semua aplikasi Visual Basic.

f. Jendela Properties

Jendela properties adalah jendela yang mengandung semua informasi mengenai object yang terdapat pada visual basic.

g. Form Layout Window

Merupaka jendela yang menggambarkan posisi dari form yang ditampilkan pada layer monitor.

h. Jendela Kode

Jendela kode adalah salah satu jendela penting dalam visual basic.

\section{Analisa Sistem yang Sedang Berjalan}

Sebelum mengembangkan dan merancang sistem yang akan dibuat, maka kita harus menganalisis bagaimana gambaran sistem yang sudah ada. Sistem yang sedang berjalan pada Berkah Catering Padang Panjang masih bersifat manual. Berikut adalah gambaran umum dari sistem penyampaian informasi yang dapat digambarkan pada sebuah Aliran Sistem Informasi (ASI).

Tabel. 1 Jangkauan Nilai Tipe Data Visual Basic

\begin{tabular}{|c|c|c|}
\hline Tipe & Jangkauan & Ukuran \\
\hline Integer & $-32.766 \mathrm{~s} / \mathrm{d} 32.767$ & 2 byte \\
\hline Long & $\begin{array}{l}-2.147 .483 .648 \mathrm{~s} / \mathrm{d} \\
2.147 .483 .647\end{array}$ & 4 byte \\
\hline Single & $\begin{array}{l}-3.403823 \mathrm{e} 38 \mathrm{~s} / \mathrm{d}-1.401298 \mathrm{e}- \\
45 \text { (negatif) } \\
1.401298 \mathrm{e}-45 \mathrm{~s} / \mathrm{d} 3.403823 \mathrm{e} 38 \\
\text { (positif) }\end{array}$ & 4 byte \\
\hline Double & $\begin{array}{l}-179769313486232 \mathrm{e} 308 \mathrm{~s} / \mathrm{d}- \\
4.9406564581247 \mathrm{e} 324 \\
\text { (negative) }\end{array}$ & 8 byte \\
\hline Currency & $\begin{array}{l}-922,337.203,685,477.5808 \mathrm{~s} / \mathrm{d} \\
922,337,203,685,477.5807\end{array}$ & 8 byte \\
\hline String & $\begin{array}{l}0 \mathrm{~s} / \mathrm{d} 65.500 \text { karakter (Win } 31) \\
0 \mathrm{~s} / \mathrm{d} 2 \text { e32 karakter (Win } \\
95 / \mathrm{NT})\end{array}$ & 1 byte \\
\hline Boolean & True atau False & 2 byte \\
\hline Date & $\begin{array}{l}1 \text { Januari } 100 \text { S/D } 31 \\
\text { Desember } 9999\end{array}$ & 8 byte \\
\hline Object & Referency Object & 4 byte \\
\hline Byte & $0 \mathrm{~s} / \mathrm{d} 255$ & 1 byte \\
\hline Variant & $\begin{array}{l}\text { Null, Error, Numeric, dengan } \\
\text { type double, character text, } \\
\text { object atau array }\end{array}$ & 16 byte \\
\hline
\end{tabular}


Tabel. 2 Baris Menu dalam Visual Basic

\begin{tabular}{|l|l|}
\hline Nama & Keterangan \\
\hline File & $\begin{array}{l}\text { Kelompok Perintah Yang Berfungsi Untuk Pengaturan Suatu File, Seperti New, Save, } \\
\text { Open, dan sebagainya. }\end{array}$ \\
\hline Edit & $\begin{array}{l}\text { Kelompok perintah untuk pengeditan, baik pengeditan object, komponen maupun } \\
\text { kode pada kode editor, contohnya Cut, Paste, Align. }\end{array}$ \\
\hline Project & $\begin{array}{l}\text { Perintah-perintah untuk mengaktifkan bagian-bagian dari Integrated Development } \\
\text { Environment VB6 }\end{array}$ \\
\hline Format & Berfungsi untuk manajemen proyek serta pendukungnya \\
\hline Debug & Kelompok perintah untuk melakukan proses format \\
\hline Run & $\begin{array}{l}\text { Berfungsi untuk menangani proses kompilasi program seperti Run, Built, Step Over, } \\
\text { Debug dan seterusnya. }\end{array}$ \\
\hline Query & $\begin{array}{l}\text { Kumpulan perintah untuk mengakses data yang diperlukan pada aplikasi database. } \\
\text { Menu ini adalah menu baru pada versi 6.0 }\end{array}$ \\
\hline Diagram & $\begin{array}{l}\text { Menyediakan perintah untuk pengaturan diagram. Diagram yang merupakan menu } \\
\text { baru pada versi 6.0 ini sangat menolong dalam proses perancangan. }\end{array}$ \\
\hline Tools & $\begin{array}{l}\text { Sebagai penyedia perlengkapan tambahan yang diperlukan dalam penyusunan } \\
\text { program. }\end{array}$ \\
\hline Add-ins & Untuk pengaturan program tambahan bagi VB6 \\
\hline Window & Pengaturan window yang sedang terbuka \\
\hline Help & Menyediakan informasi untuk menolong pemakai dalam menggunakan VB6 \\
\hline
\end{tabular}

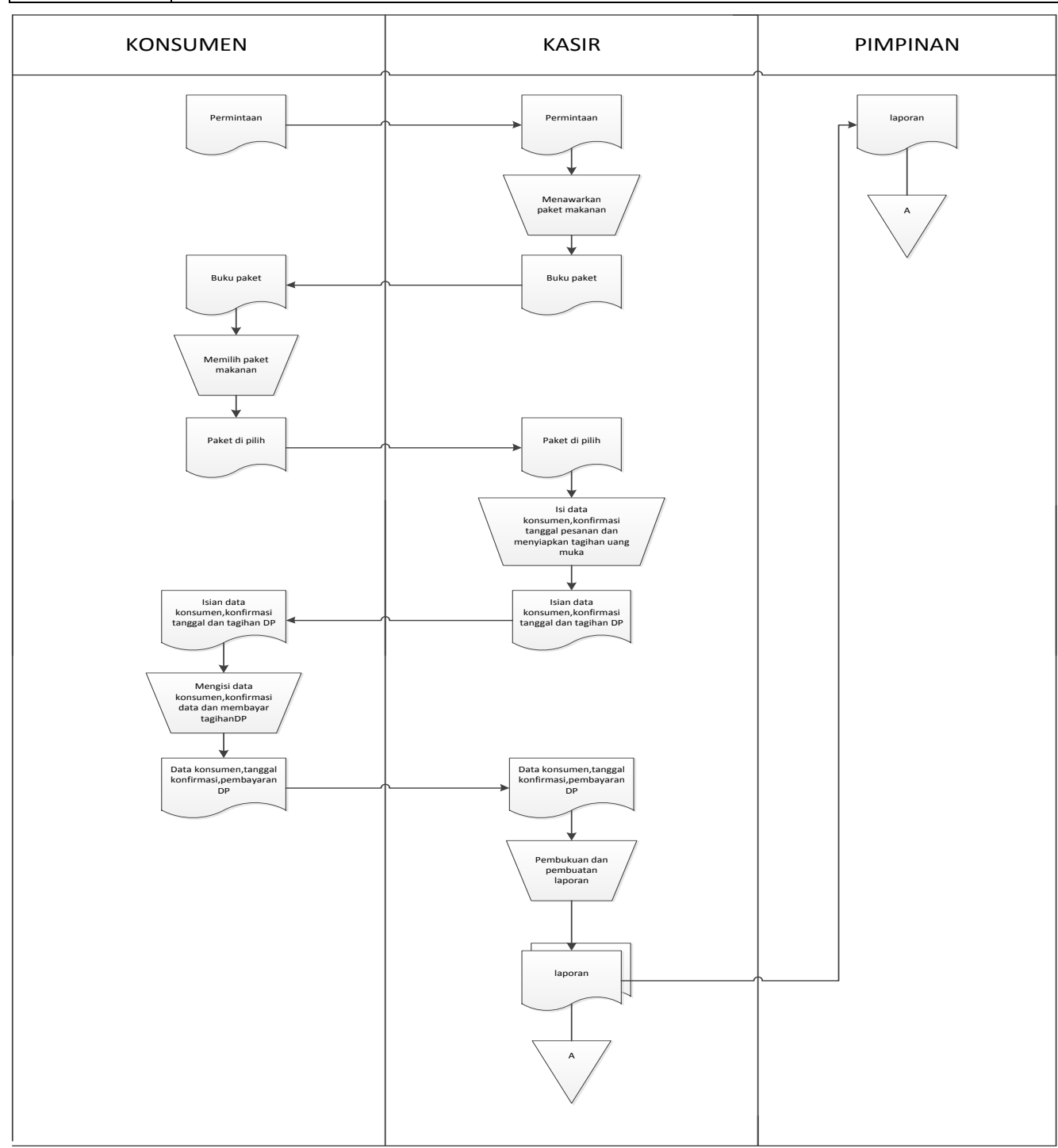

Gambar .1 Aliran Sistem Informasi yang sedang berjalan 
Berdasarkan gambar diatas dapat dijelaskan sebagai berikut :

a. Konsumen melakukan order / menanyakan cara pemesanan catering.

b. Kemudian kasir mengeluarkan buku paket menu yang akan di pilih konsumen

c. Setelah itu konsumen memilih paket menu makanan .

d. Kemudian konsumen mengisi data, konfirmasi tanggal pesanan dan menyiapkan tagihan uang muka.

e. konsumen melakukan validasi / pembayaran dan menyerahkan kepada kasir. f. Setelah diterima oleh kasir,kasir membuat laporan dan memberikan laporan tersebut kepada pimpinan.

\section{Perancangan Sistem Baru}

Desain sistem dapat dibagi dalam dua bagian, yaitu desain sistem secara umum (general systems design) dan desain sistem terinci (detailed systems design) desain sistem secara umum disebut juga dengan desain secara makro (macro design). Desain sistem terinci disebut juga dengan desain sistem secara phisik (physical system design) atau desain internal (internal design).

\section{ALIRAN SITEM INFORMASI (ASI) BARU}

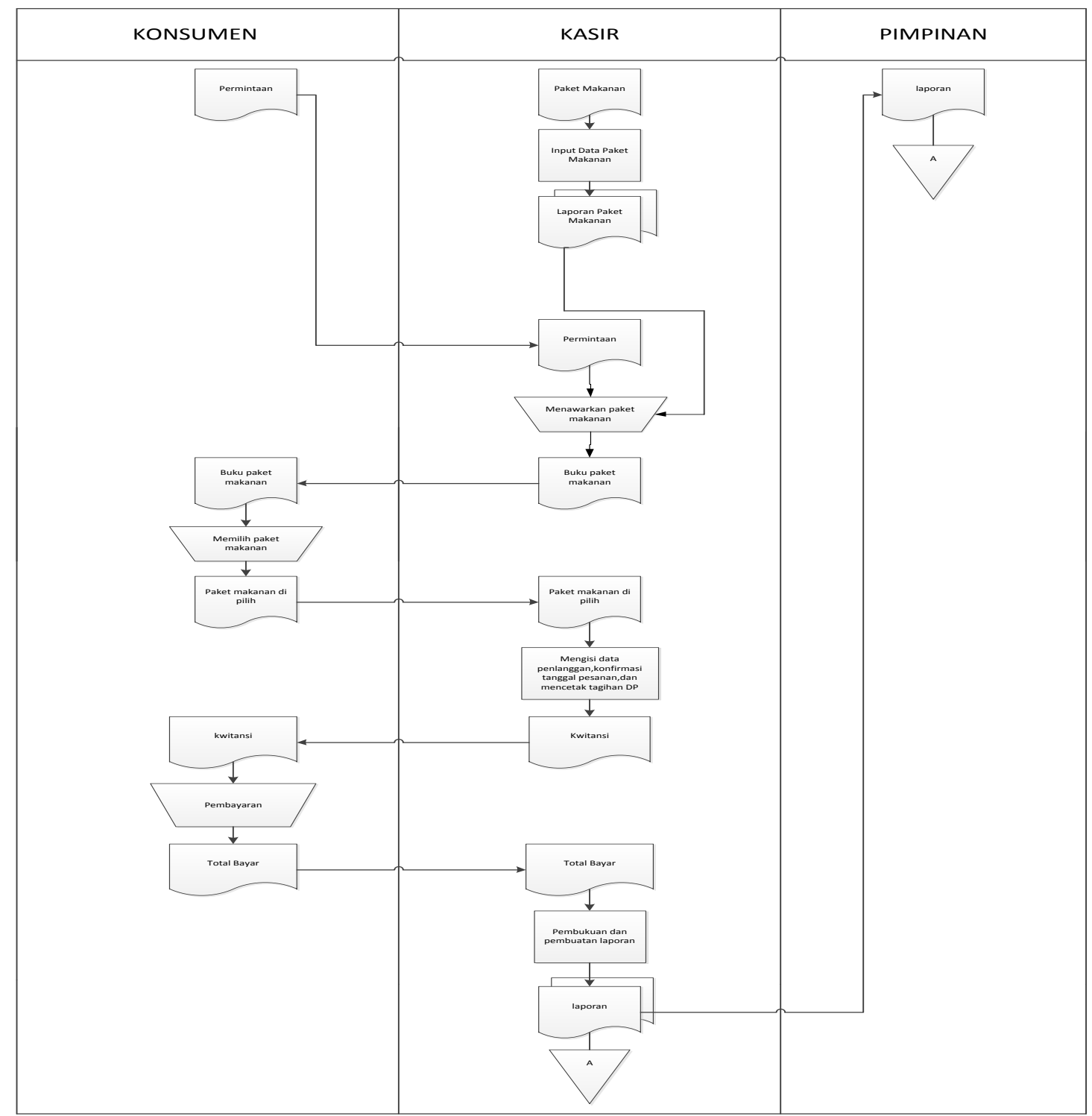

Gambar. 2 Aliran Sistem Informasi (ASI) Baru 


\section{CONTEXT DIAGRAM}

- Permntaan

Paket pilihan

- Input paket

- pembayaran

- Permintaan

- Paket pilihan

- pembayaran

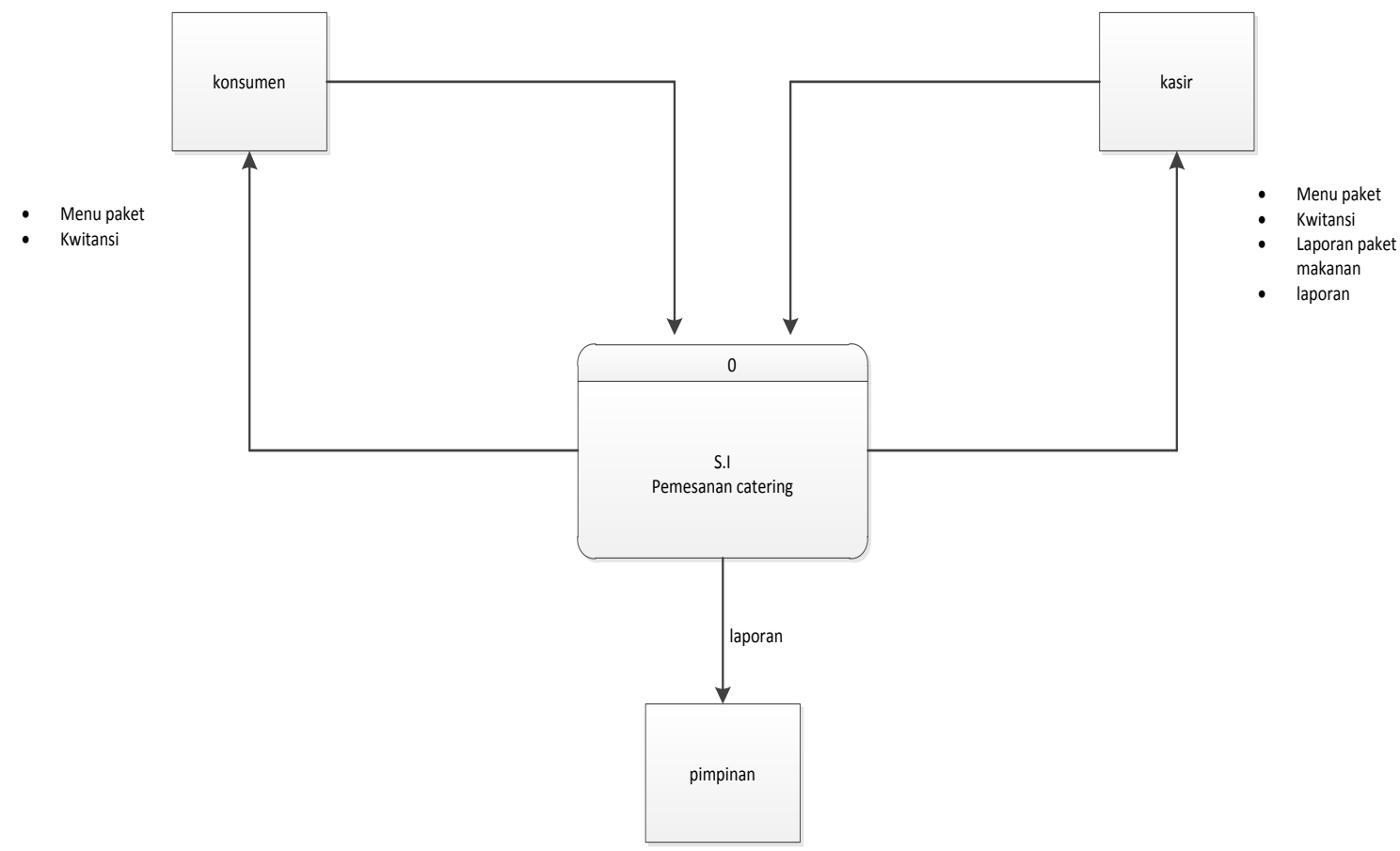

Gambar. 3 Context Diagram

DATA FLOW DIAGRAM (DFD)

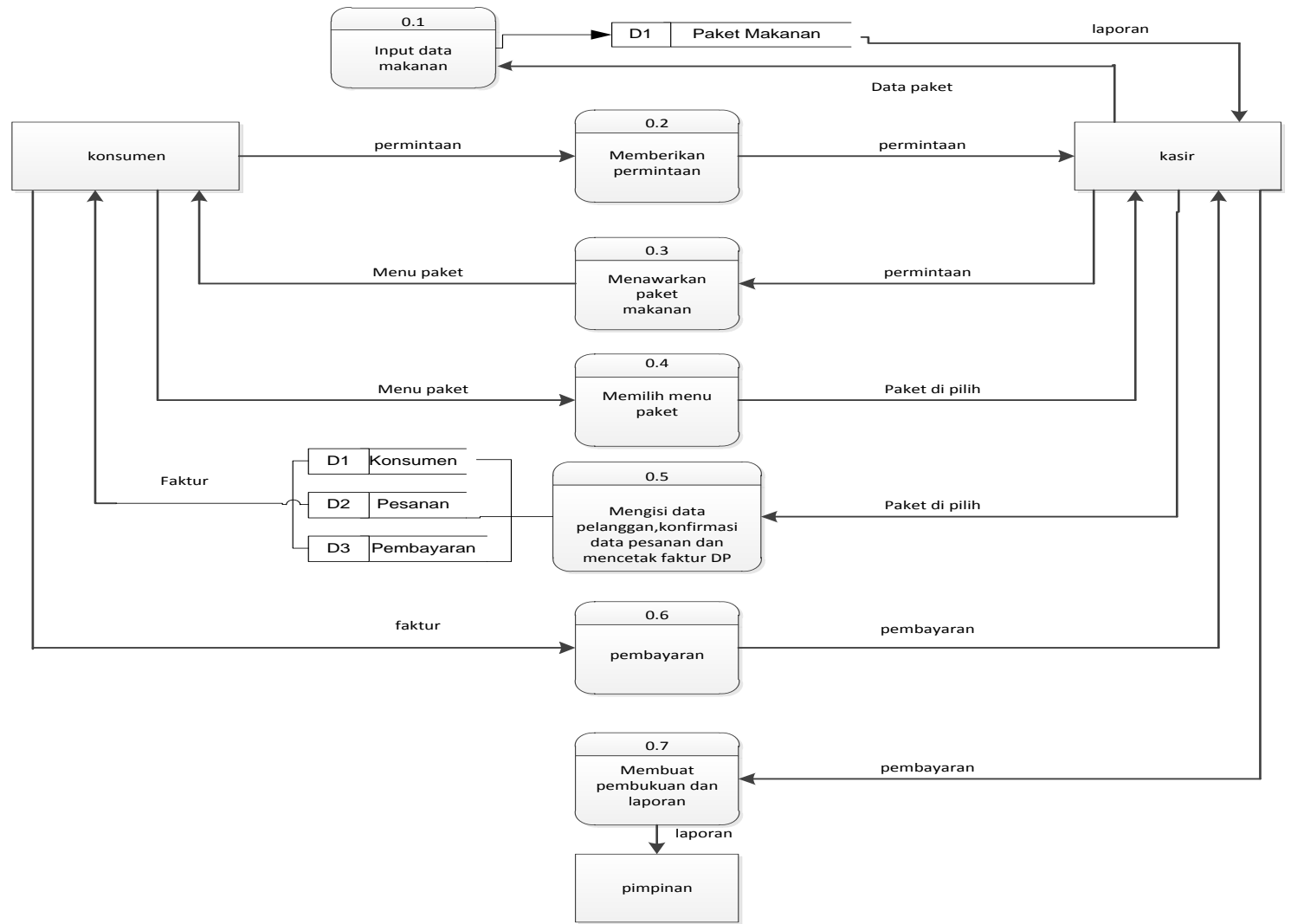

Gambar. 4 Data Flow Diagram 


\section{ENTITY RELATIONSHIP DIAGRAM}

ERD (Entity Relationship Diagram)

adalah suatu model untuk menjelaskan hubungan antar data dalam basis data berdasarkan objek-objek dasar data yang mempunyai hubungan antar relasi. ERD untuk memodelkan struktur data dan hubungan antar data, untuk menggambarkannya digunakan beberapa notasi dan simbol.

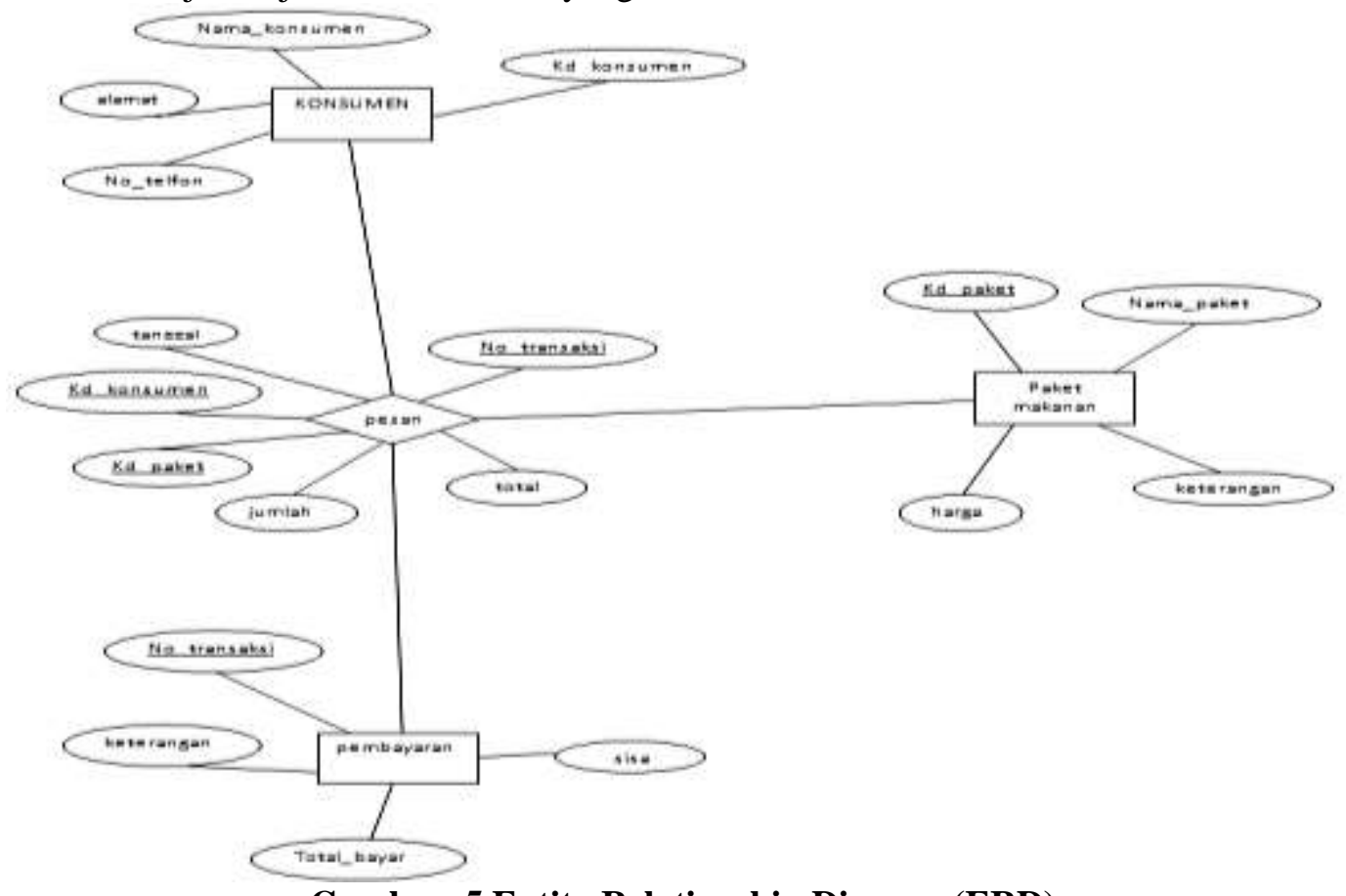

Gambar. 5 Entity Relationship Diagram(ERD)

\section{Desain Input}

Masukkan atau input merupakan awal dimulainya proses informasi. Bahan mentah dari informasi adalah data yang terjadi dari transaksi yang dilakukan oleh Organisasi, Dinas atau Instansi.

\section{Desain Form Login}

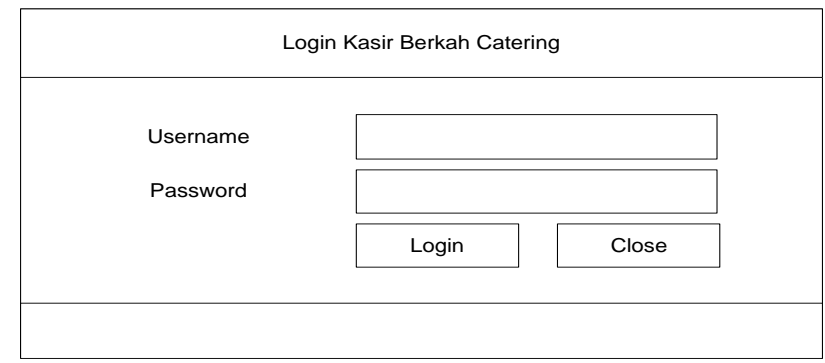

Gambar.6 Desain Form Login

\section{Desain Form Menu Utama}

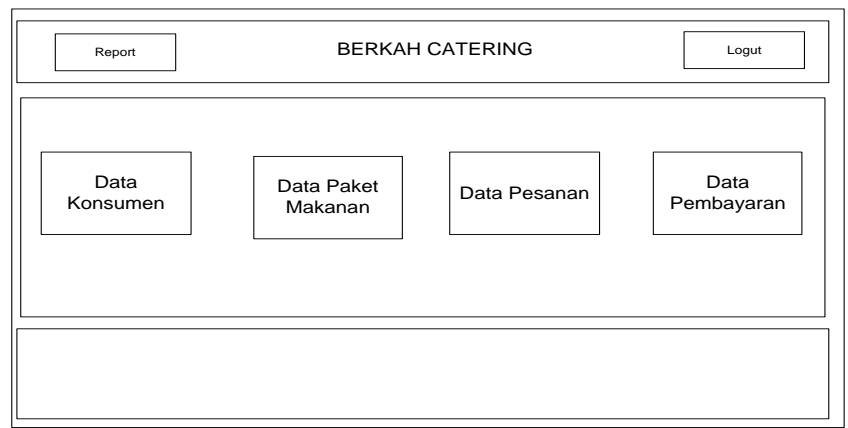

Gambar. 7 Desain Form Menu Utama 
Desain Form Input Data Konsumen

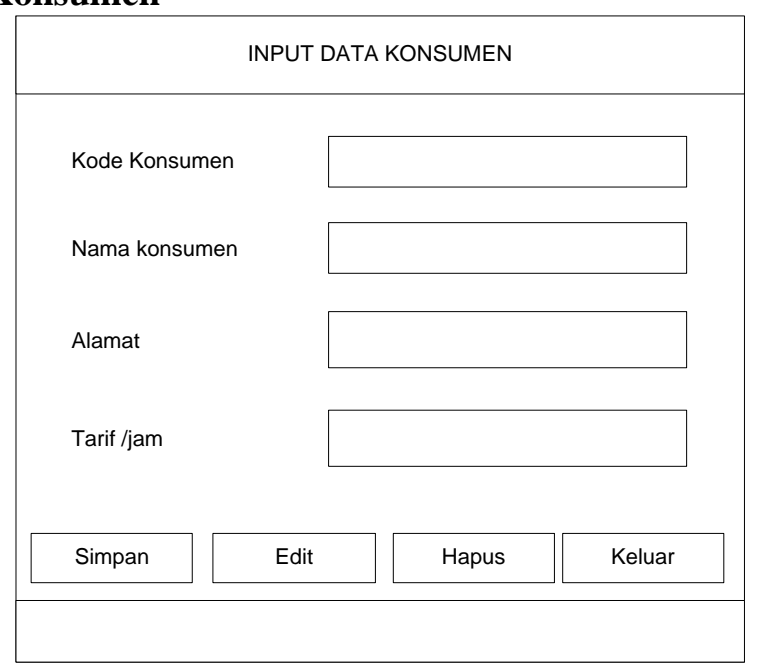

Gambar. 8 Desain Form Input Data Konsumen

Desain Form Input Data Paket Makanan

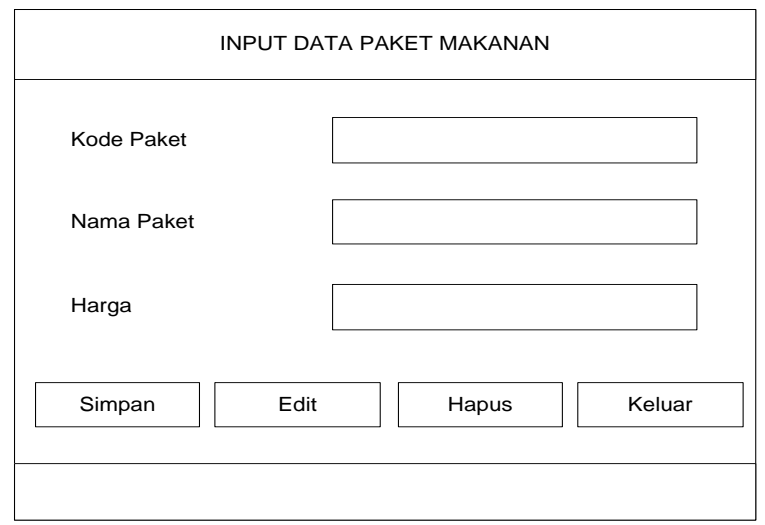

Gambar. 9 Desain Form Input Data Paket Makanan

Desain Form Input Data Pesanan

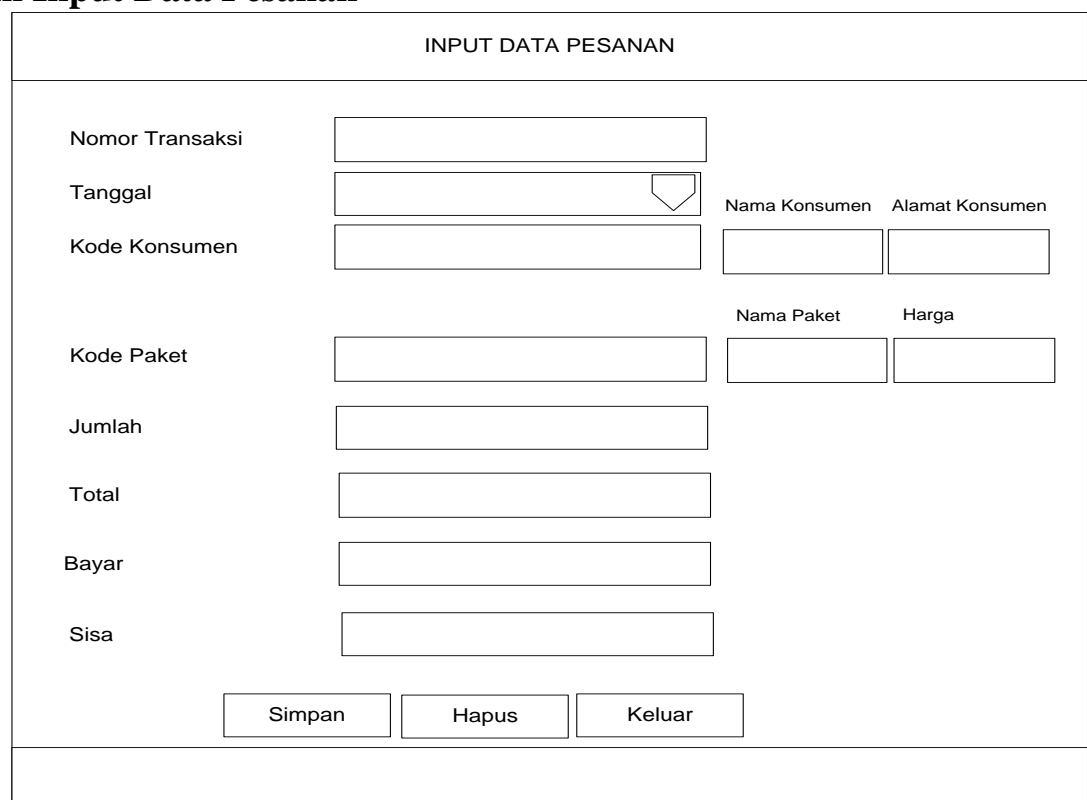

Gambar.10 Desain Form Input Data Pemesanan 
Desain Form Input Data Pembayaran

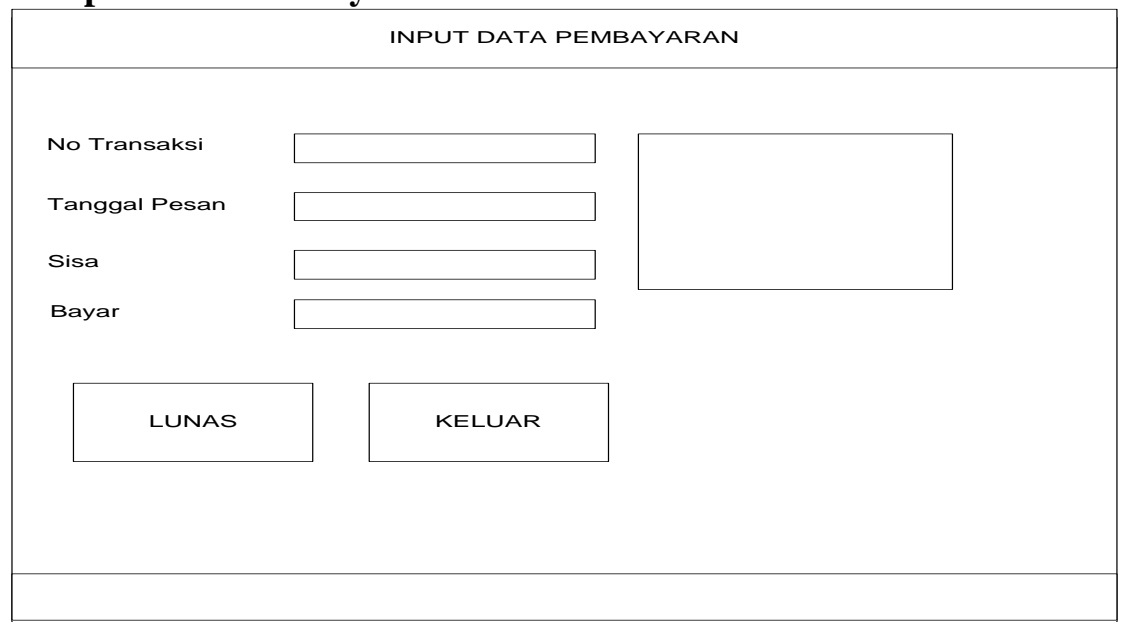

Gambar 11 Desain Form Input Data Pembayaran

\section{Desain Form Laporan}

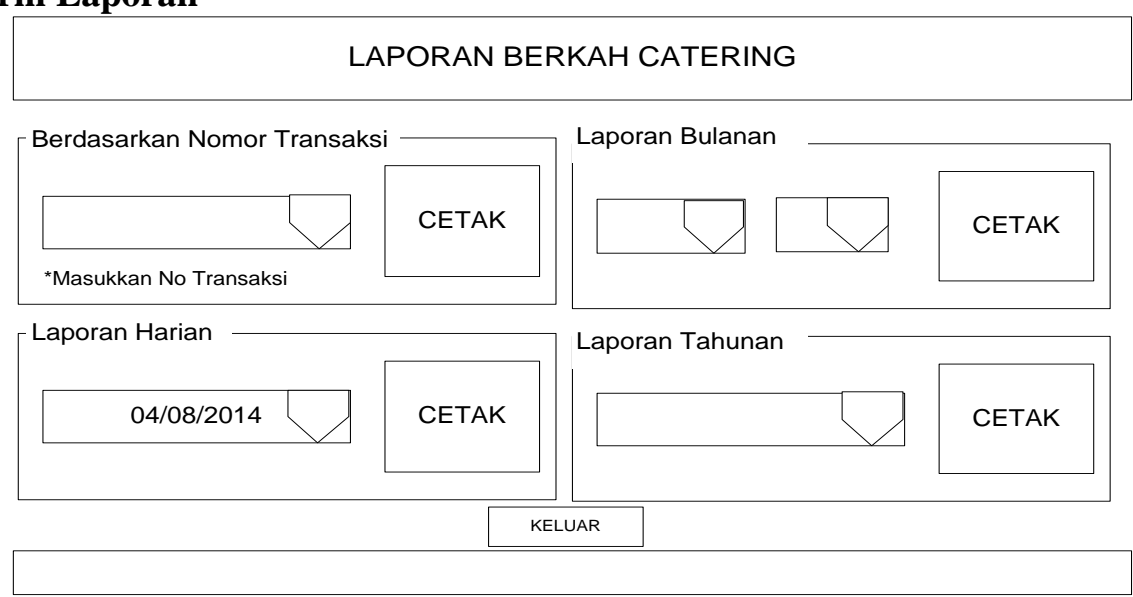

Gambar. 12 Desain Form Input Data Pembayaran

\section{Desain Output}

Output merupakan hasil dari proses yang disajikan dalam bentuk laporan. Perancangan output digunakan untuk memenuhi kebutuhan informasi dengan melalui instruksi tertentu.

\section{Laporan Nota Pembayaran}

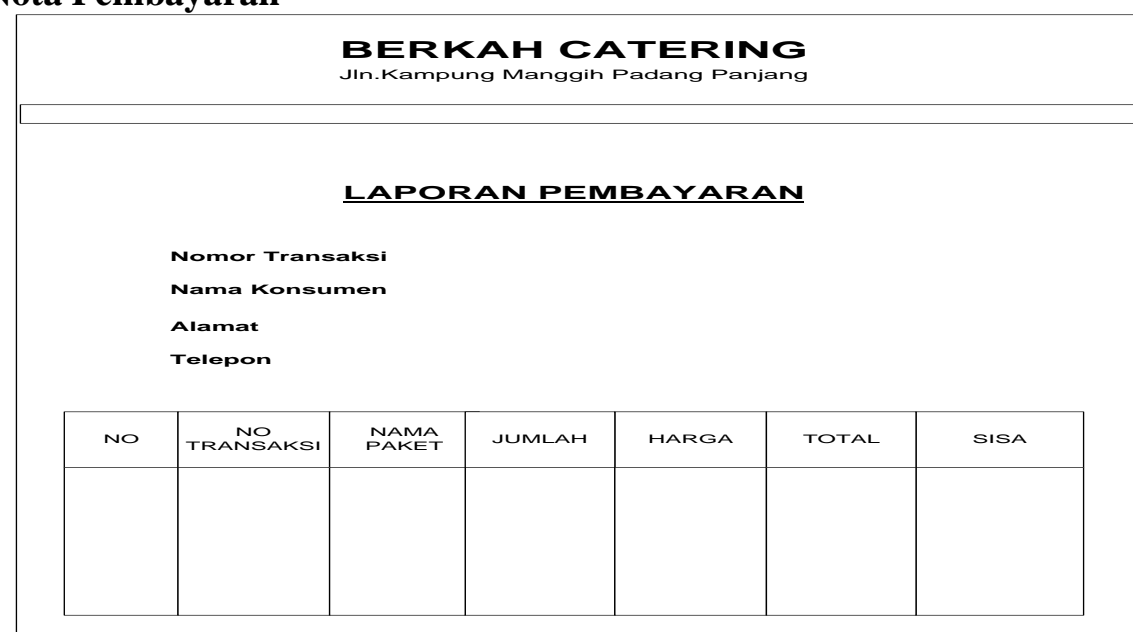

Gambar. 13 Laporan Nota Pembayaran 
Laporan Pendapatan Harian

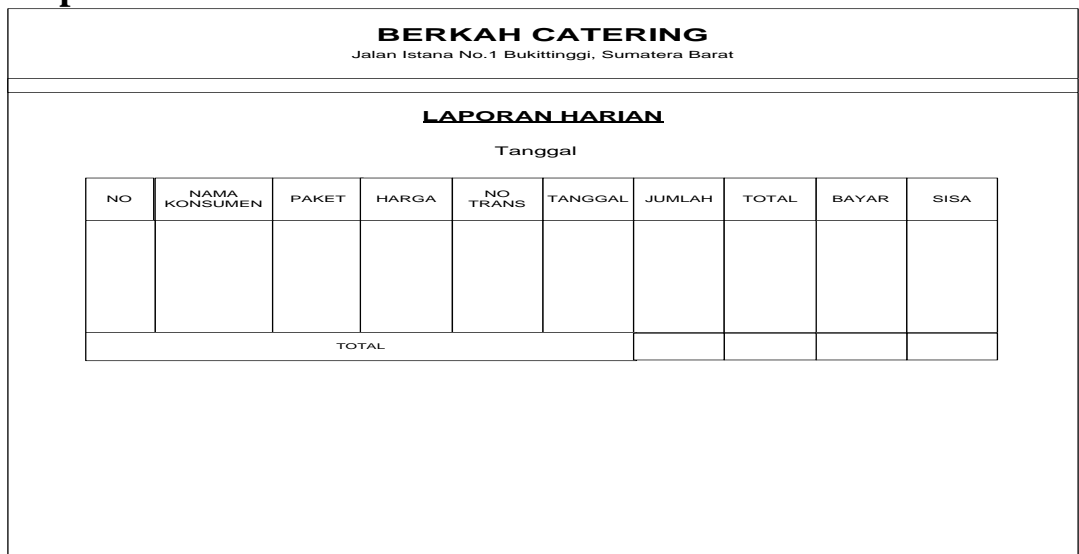

Gambar 14. Laporan Pendapatan Harian

Laporan Pendapatan Bulanan

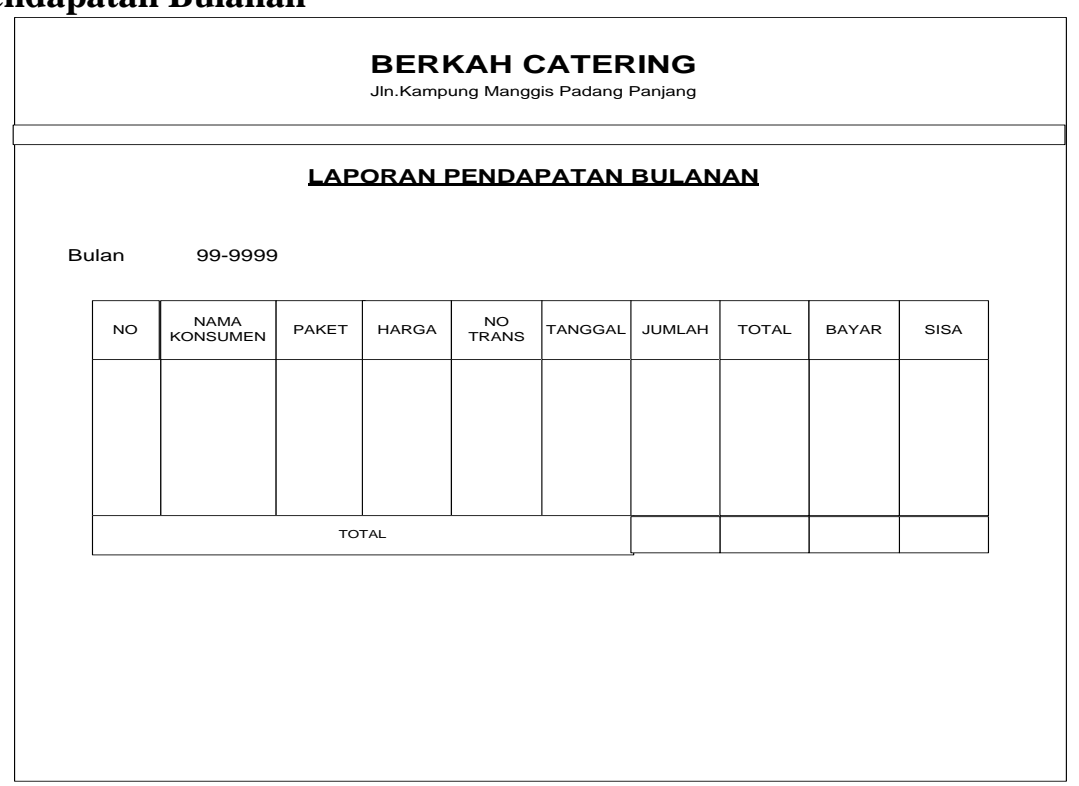

Gambar 15. Laporan Pendapatan Bulanan

Laporan Pendapatan Tahunan

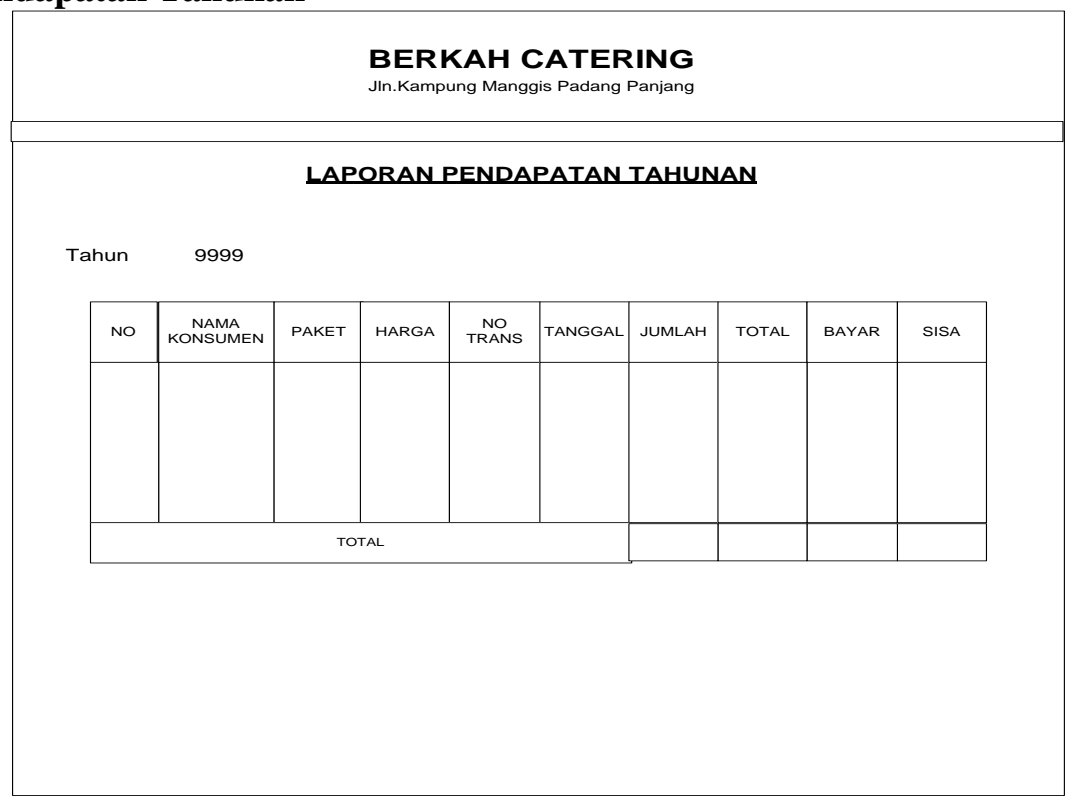

Gambar. 16 Laporan Pendapatan Tahunan 


\section{PENUTUP}

\section{KESIMPULAN}

Dengan Sistem Informasi Pemesanan

Makanan Pada Berkah Catering Padang

Panjang Berbasis Microsoft Visual Bassic 6.0.

1. Dengan adanya aplikasi system informasi pemesanan makanan ini maka kesalahankesalahan yang bersifat human error dapat di minimalisir.

2. Dengan adanya aplikasi sistem informasi pemesanan ini maka dalam proses pembuatan laporan lebih cepat.

\section{SARAN}

Setelah menganalisa masalah dari tempat penelitian, hendaknya Berkah Catering menggunakan sistem yang telah terkomputerisasi sehingga dalam pendokumentasian data maupun proses transaksi itu sendiri dapat diproses dengan mudah. Dalam pembuatan laporan pun akan lebih akurat dan tidak memerlukan waktu yang banyak. Sehingga tercipta kinerja yang baik dan terintegrasi pada Berkah Catering,karena tepat waktu merupakan salah satu kualitas dari informasi.

Walaupun sistem informasi transaksi yang dirancang dapat memberikan solusi tentang permasalahan yang terjadi, namun sistem yang dirancang masih sangat jauh dari sempurna.Maka dari itu Penulis memberikan saran-saran sebagai berikut:

1. Sistem informasi yang telah dibangun ini agar dijadikan bahan untuk pengembangan sistem lebih lanjut.

2. Untuk dapat menjalankan aplikasi Basis Data ini, sebaiknya pihak dari Berkah Catering mengadakan pelatihan untuk kasir yang akan membuat pendataan pemesanan dan pembuatan laporan.
3. Perancangan system yang baru ini belum sempurna, masih terdapat kekurangan seperti : Belum bisa untuk pengembangan pemasaran, karena system tersebut belum berjalan secara online.Untuk itu diharapkan bagi pengembang yang akan mengembangkan sistem ini agar dapat mengatasi masalah tersebut.

\section{DAFTAR PUSTAKA}

Budiharjo. 2006. Sistem Informasi Manajemen,Diklat KPC

Pemrograman(Bisnis). Bidang

Pendidikan dan Pelatihan Pusat Komputer PIKSI ITB.

Dinaonnya. 2010. Pengertian Sistem Informasi.http://f123dynaonnya.wordpr ess.com (diakses pada tanggal 27 Juni 2013

Gorden B, Davis. 2003. Kerangka Dasar Sistem Informasi Manajemen Bagian I. Jakarta : IPPM.

H.M, Jogiyanto. 2001. Analisis dan Desain Sistem Informasi. Yogyakarta: Andi Offset.

H.M, Jogiyanto. 2005. Pengenalan Komputer. Yogyakarta: Andi Offset.

Jogiyanto. 2003. Analisis Desain. Yogyakarta : Andi Pengertian Sistem Informasi (http://f123dynaonnya.wordpress.com/2 013/06/25/pengertian-sisteminformasi/)

Razaq, Abdul. 2004. Belajar Cepat Visual Basic 6.0. Yogyakarta : Indah Surabaya.

Sistem Informasi

(http://irsyafseptiari.blogspot. com/2013/01/06/systeminformasi.html) 